introduced precisely when required and, if necessary, repeated.

Mr. C. J. Duncan (University of Durham, King's College, Newcastle upon Tyne) said that the normal 'instructional film' with its elaborate production, titling and sound commentary was quite unsuited to the university lecture; what is required is a short piece of film which illustrates only the essential event in which the movement being dealt with occurs. As an example, Mr. Duncan demonstrated how, in describing a piece of apparatus, its components could all be shown by slides, thus enabling the speed of explanation to be varied on different occasions and the moving sequence showing the apparatus in use could be projected at the appropriate moment. This method is of value in that it avoids the necessity of producing a complete film with all the necessary editing and titling, and so is much less expensive than an instructional film; also it is much more flexible and any subsequent modification of the apparatus or technique being demonstrated merely necessitates the substitution of a small piece of film and not the production of a completely new fulllength film. These short films lasting some $15-20$ sec. can be called 'moving diapositives', and if several are joined together by short lengths of blank film, during which the projector is stopped, several such short sequences can be shown in one lecture without re-threading the projector and thus disturbing the lecture.

Prof. H. I. Stonehill (Royal Military College of Science, Shrivenham) reviewed the use of television as a medium of instruction at college- and universitylevel in the United States, emphasizing how much this method was being employed there for instruction at all levels. In discussing in more detail its use in universities an account of some assessments of its value was given ; apparently, results so far indicate that students 'attending' lectures by television do as well in tests as those actually present in the lecture room. Some students were reported to prefer television lectures because, when concentrating on the screen, they had less difficulty in preventing their attention from wandering than when in a large audience.

Mr. A. M. P. Brookes (Cambridge) described experiments now going on in the Engineering Labor- atories at Cambridge where, on account of large numbers, some students were 'attending' the lectures in an adjacent room to which the lecture was televised. The lectures involved were those given by Mr. Brookes himself, and he told of the first attempt and the modifications in technique that had been made in succeeding lectures. Small television cameras can be set up in the lecture room without waste of space, so sited that they cover the movements of the lecturer and show the blackboards clearly. It is important that the lecturer should appear in the picture in reasonable proportion when seen against the blackboard; close-ups which tend to turn the lecturer into a 'television personality' are to be avoided. The necessity for keeping in view of the television cameras does tend somewhat to limit the movement of the lecturer on his rostrum. It is of great importance that the camera covering any one blackboard remains in use long enough for students to copy any diagram or note which it is expected they shall copy. At present, $\mathrm{Mr}$. Brookes and his colleagues are learning by trial and error, but inspection of students' note-books indicates that those receiving the lecture by television make as full notes as those in the lecture-room.

Iuring a general discussion which followed, Mr. Brookes, with the aid of the equipment present, gave a demonstration of 'blackboard work' by television.

T'his session covered a wide field, and while little summary is possible, attention may be directed to the point made by several speakers that films and television are so well adapted to mass instruction that their possible uses at university-level tend to be overlooked. This is particularly so with films, for although instructional films have been available for many years, suitable film illustration for a university lecture is hard to come by. This, as has already been suggested, is because instructional films are produced as complete entities. There is a need for the provision of short lengths of film illustrating those particular points, which are found in several sciences, when movement plays such an essential part that it cannot be illustrated by other means. Whether this can be done on a commercial basis or whether such sequences, perhaps produced in the course of research, ean be exchanged between university departments remains to be seen.
G. E. H. Foxon

\title{
THE HALDEN (NORWAY) REACTOR
}

\begin{abstract}
HE boiling heavy-water reactor of the Norwegian Institutt for Atomenergi at Halden, which is to be used for a joint programme of research and experiment organized by the Organization for European Economic Co-operation, European Nuclear Energy Agency, was successfully operated for the first time on June 29, 1959. The reactor, moderated and cooled with heavy water and fuelled with natural uranium, is located in an excavation in a rock near the paper and pulp factory Saugbrugsforeningen in Halden, $120 \mathrm{~km}$. south of Oslo. It is the first boiling heavy-water reactor in the world, and the first boiling-water reactor in Europe. Besides its main function as a power demonstration reactor for studying problems associated with boiling heavywater reactor systems, the installation will also produce some 15 tons per hour of process steam in the secondary light-water circuit. Eventually this
\end{abstract}

steam will be used in the paper factory and it is believed that this will be the first nuclear process steam installation.

The reactor was designed at the NetherlandsNorwegian Joint Establishment for Nuclear Energy Research, Kjeller, and was built by the Norwegian Institutt for Atomenergi. The main sub-contractor's were the Kvaerner-Myhren, -Thune Combine (mechanical installations), the $\mathrm{Chr}$. Michelsens Institutt (control and instrumentation), Hoyer Ellefsen (civil engineering work), the U.K. Atomic Energy Authority (fuel), and the U.S. Atomic Energy Commission (heavy water). The total cost of the plant, including heavy water and the first uranium fuel load, was $3 \cdot 5$ million dollars.

The Organization for European Economic Cooperation Agreement concerning the reactor was signed in June 1958 by Austria, Denmark, Euratom 
(representing Belgium, France, Germany, Italy, Luxembourg and the Netherlands), Norway, Sweden, Switzerland and the United Kingdom. It provides for a joint programme, budget and staff for research and development work with the reactor for a period of three years. Through agreements with the Institutt for Atomenergi, the United States and Finland are also associated with the reactor project. At present, a professional staff of thirty, recruited from the participating countries, is attached to the project. During the next six months the reactor will be operated at low power-levels to enable fundamental reactor physics experiments to be performed. After this period the power level will be increased gradually up to the design power of $10 \mathrm{MW}$. thermal energy.

The reactor plant will be officially opened by H.M. King Olav on October 10.

The Halden Reactor Project is one of several joint undertakings sponsored by the European Nuclear Energy Agency of the Organization for European Economic Co-operation; others are the 'Eurochomie' company for the chemical processing of irradiated fuels (established by an international convention signed in December 1957) and the Dragon hightemperature gas-cooled reactor project, work on which began last April.

\section{THE DANISH ATOMIC}

T THE report on the activities of the Danish Atomie Energy Commission* for the period April 1, 1957, to March 31, 1958, deals mainly with the erection of the Risø Research Establishment and the three reactors $D R 1, D R 2$ and $D R 3$, and the work of the six departments of the Establishment. The membership of the Commission remained unchanged during the period under review, and Prof. Niels Bohr continued to act as chairman. The total cost of the Establishment was originally estimated at about 100 million kroner. The expenditure so far, including that estimated for 1958-59, is about 90 million kroner, of which about 60 million kroner is for expenditure on buildings and the remainder for the three reactors and the requisite technical and scientific equipment. On March 26, 1958, the Finance Committee authorized an additional expenditure of up to $2 \cdot 5$ million kroner on a linear accelerator to be used for experiments on the preservation of food and for other irradiation experiments.

On August 15, 1957, the first of the three reactors began to operate, and by September the chemical, reactor engineering, electronics and physics laboratories together with the administration building were completed and in use. Then followed the health physics department, the library and the canteen, and early in 1958 the agricultural department, the lecture hall and the buildings to house the DR2

* Report on the Activities of the Danish Atomic Finergy Commission for the period from 1 April 1957 to 31 March 1958. Pp. 62. (Copenhagen: Danish Atomic Fnergy Commission, 1958.)

\section{ENERGY COMMISSION}

reactor group were completed, leaving only the buildings for the $D R 3$ reactor to be erected. A detailed map attached to the report shows the complete layout of the Establishment.

In the physics department one group has been working on the construction of a laboratory for investigations of beta- and gamma-ray activities; another group with neutron spectroscopy; and a third group with solid state physics, particularly the study of the effects of radiation damage to metals and graphite. A study has also been made of the literature on deuterium fusion and of the theoretical aspects of the utilization of the energy from deuterium fusion. The electronics department has undertaken active research on scintillation counters and on the development of a reactor simulator. Two study groups were formed in the reactor engineering department. The first was engaged in drafting a project for a heavy-water-moderated power reactor with an organic cooling medium, and the sccond for a high-temperature gas-cooled reactor.

A section of the report is devoted to the International Atomic Energy Ageney, and to regional co-operation in Europe, including the Organization for European Economic Co-operation and Euratom. The report also gives details of geological surveys in Greenland; relations between the Commission and commerce and industry; educational activities which included experimental reactor courses with $D R 1$ and lecture courses at the Technical Universitr of Denmark; and general information services.

\section{ATOMIC POWER CONSTRUCTIONS, LTD.}

$\mathrm{A}^{\mathrm{T}}$ TOMIC POWER CONSTRUCTIONS, LTD., 28 Theobalds Road, London, W.C.1, which was formed in December 1956, is carrying out extensive research and development in connexion with the national nuclear power effort. The research programme is concentrated at the company's laboratories at Heston, Middlesex, and a booklet* recently prepared gives a survey of the problems being tackled. In the Calder Hall type of reactor the uranium is arranged in a pattern of vertical rods embedded in a large cylindrical 'core' of graphite. The heat generated in the rods is carried away by blowing carbon dioxide gas past them, and in order to economize in pumping power the reactor designer puts the

* Research and Development at the Heston Laboratories of Atomic Power Constructions, Limited. Pp. 10. (London: Atomic Pore Constructions, Ltd., 1959.) whole of the carbon dioxide gas circuit under a pressure of some 20 atmospheres. Consequently, the core and uranium must be enclosed in a pressure vessel.

Most stringent precautions must be taken against failure of the pressure circuit in which the carbon dioxide circulates, and a major part of the work undertaken by Atomic Power Constructions, Ltd., is concerned with proving the materials and fabrication techniques which are used in the construction of the pressure vessel. An important problem is creep of the steel to be used for the pressure vessel and for the heat exchangers, and in order to aequire the necessary information sufficiently quickly an airconditioned creep laboratory containing a battery of seventy creep machines has been set up. The strain ageing of steels at elevated temperatures; weld- 